University of Nebraska - Lincoln

DigitalCommons@University of Nebraska - Lincoln

1978

\title{
Food deprivation and the regulation of meal size in larvae of Chrysopa carnea
}

Alan B. Bond

University of Nebraska - Lincoln, abond1@unl.edu

Follow this and additional works at: https://digitalcommons.unl.edu/bioscibond

Part of the Behavior and Ethology Commons

Bond, Alan B., "Food deprivation and the regulation of meal size in larvae of Chrysopa carnea" (1978). Alan Bond Publications. 8.

https://digitalcommons.unl.edu/bioscibond/8

This Article is brought to you for free and open access by the Papers in the Biological Sciences at DigitalCommons@University of Nebraska - Lincoln. It has been accepted for inclusion in Alan Bond Publications by an authorized administrator of DigitalCommons@University of Nebraska - Lincoln. 
Published in Physiological Entomology 3 (1978), pp. 27-32. Copyright @ 1978 Blackwell Scientific Publications. Published for the Royal Entomological Society of London. Used by permission.

Accepted September 5, 1977

\title{
Food deprivation and the regulation of meal size in larvae of Chrysopa carnea
}

\author{
Alan B. Bond \\ Department of Zoology, University of California, Berkeley, California
}

\begin{abstract}
The course of repletion and the effects of food deprivation on meal size were explored in three experiments on larvae of Chrysopa carnea (Neuroptera). Feeding to repletion was found to occur within the first 30 min of exposure to food. Meal size increased as an ogival function of deprivation, up to the limit of gut capacity. Behavioral components involved in the initiation of feeding were little affected by deprivation and did not appear to be inhibited by distention of the gut. Termination of a meal may be mediated by the stimulation of prey-release behavior, rather than by inhibition of feeding.
\end{abstract}

\section{Introduction}

Meal size, defined as the amount of material ingested during a single bout of feeding, has commonly been observed to increase with food deprivation at a progressively decreasing rate, approaching a maximum asymptotic value. The pattern of increase often appears to reflect the dynamics of muscular evacuation of some storage component of the digestive system (Barton Browne, 1975; Holling, 1966; Hunt \& Spurrell, 1951; Dufort \& Wright, 1962). Several authors have fitted exponential curves to these data, under the assumption that the rate of evacuation can be considered a linear function of the volume of gut contents (Holling, 1966; Hunt \& Spurrell, 1951). Evidence in support of this assumption is available from studies of gut emptying in several disparate species (Green, 1964; Davey \& Treherne, 1963; Quigley \& Louckes, 1962).

Inhibitory influences from mechano-receptors in the gut and abdomen have been implicated as the principal active agencies in regulating meal size and duration in several insect species (review in Barton Browne, 1975). Chemoreceptors responding to feeding stimulants appear to adapt rapidly during sustained ingestion and may therefore play only a minor role in the determination of meal size. Whether these generalizations, derived mainly from studies of Diptera and Orthoptera, apply equally well to the digestive physiology of other insect groups is not known.

The larvae of the Chrysopidae are unusual among insects in that their lack of a patent connection between midgut and proctodeum precludes bulk movement of ingesta through the digestive tract (Killington, 1936). Solid waste materials accumulate in the midgut as a blackbrown, viscid mass and are excreted following the imaginal molt. Emptying the crop and midgut is thus entirely a consequence of absorption, a situation unlike that encountered in most other animals. The peculiarities of their digestive morphology suggest that the regulation of feeding in chrysopid larvae may entail rather different physiological mechanisms from those described from better-known species. A study of the influence of deprivation on feeding behavior and meal size in these insects may help to elucidate some of the features of the regulatory mechanism. 


\section{Materials and Methods}

The course of repletion, as indicated by the amount consumed and the duration of feeding behavior, and the effects of food deprivation on meal size were explored in a series of three experiments on the predatory larvae of Chrysopa carnea Stephens (Neuroptera, Chrysopidae), a common green lacewing. Eggs were obtained from a laboratory culture maintained at the University of California Agricultural Experiment Station in Albany, California. All animals used in this study were second to tenth generation descendants of adults captured in the field. The larvae were reared in individual $15-\mathrm{ml}$ vials in a controlled environment: $21.0 \pm 0.5^{\circ} \mathrm{C}, \mathrm{c}$. 50\% R.H., and a 16 h light: 8 h dark light cycle. Freshly-killed pea aphids, Acyrthosiphon pisum, were supplied in excess once daily. Experiments were conducted on the day following the first moult, about 7-8 days after hatching.

Preliminary observations indicated that chrysopid larvae do not maintain themselves at uniform levels of hunger in the rearing vials, even when provided with superabundant prey, but that confinement for $30 \mathrm{~min}$ in continuous contact with food apparently suffices to induce satiety. To substantiate these observations, it was necessary to follow the course of repletion during extended feeding sessions before and after a period of food deprivation. Confined singly in weighing capsules, nine larvae were supplied with an excess of late-instar pea aphids and allowed to feed ad libitum for $90 \mathrm{~min}$. The residual food was then removed, and the animals were kept without food for $3 \mathrm{~h}$. A fresh sample of aphids was then introduced, and another 90-min feeding period ensued. Weights of larvae and aphids were determined at successive 30-min intervals for the course of the experiment on a Cahn M-10 Electrobalance.

To examine the relationship between meal size and degree of deprivation, twenty animals in each of six treatment groups were fed to satiety and deprived for set periods of up to 12 h. Meal size was estimated from the increase in larval weight during a subsequent 30-min feeding period.

For observations of the frequency and duration of feeding episodes under confined con- ditions, nine larvae in each of two treatment groups were fed to satiety and deprived for either 2 or $8 \mathrm{~h}$. They were then confined individually in $27 \times 8 \mathrm{~mm}$ Syracuse watch glasses and provided with four to six freshly-killed, late-instar pea aphids. The number and duration of apparent feeding episodes were recorded every 15 min during a 90-min feeding session.

\section{Results}

A significant increase in larval weight was observed only within the first 30 min of feeding in the repletion experiment (Figure $1 ; P<0.001$ ). The larvae lost a small but consistent amount of weight during deprivation, about $0.056 \mathrm{mg} / \mathrm{h}$. The aphids exhibited a significant loss of weight during all intervals of the feeding periods (Figure $1 ; P<0.001)$.

Within each treatment group, meal size showed a significant linear correlation with post-satiation body weight. The correlation was negative in the undeprived controls $(r=-0.54 ; P$ $<0.01$ ), but positive at higher levels of deprivation ( $r$ between 0.44 and $0.87 ; P<0.025)$. Analysis of covariance among the experimental treatments showed no significant heterogeneity of regression coefficients, so the meal size data were adjusted for effects of body weight using a pooled slope estimate.

An ogival curve was fitted to these data using Eisenthal \& Cornish-Bowden's (1974) direct linear plot, which produces a form of hyperbola (Figure 2). The log-linear transform suggested by Holling (1966) was not used, since it necessarily produces an estimate of the maximum asympote in excess of the largest ordinal value. Holling's technique is also subject to the criticisms leveled by Cornish-Bowden \& Eisenthal (1974) at the use of linear transformations in studies of enzyme kinetics: it assumes a normal distribution of error and is highly sensitive to outlier points.

Larvae confined with an excess of food spent a substantial proportion of their time in apparent feeding activity (Figure 3), even during the last hour of exposure, when the repletion experiment revealed no significant weight increase. Throughout the period of observation, animals subjected to longer deprivations 


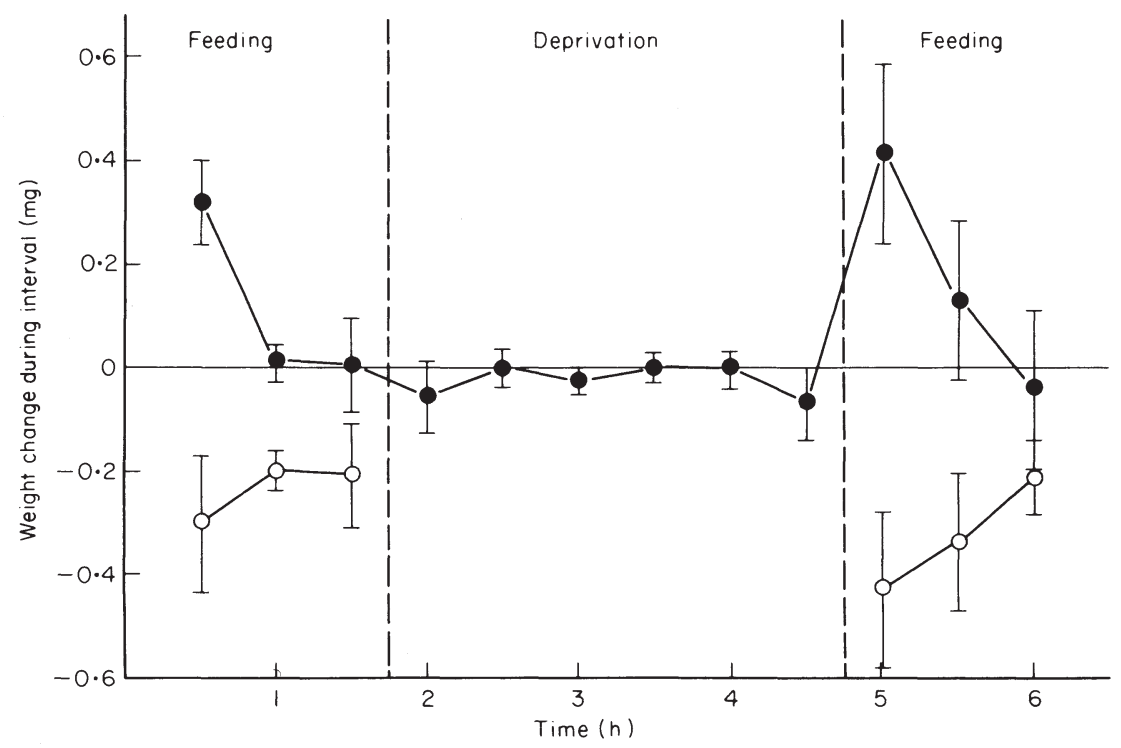

Figure 1. Weight changes during feeding and food deprivation in Chrysopa larvae; data from the repletion experiment. Filled circles indicate Chrysopa larval weights; open circles indicate weight of food items (aphids). Points are means and 95\% confidence limits of nine replications.

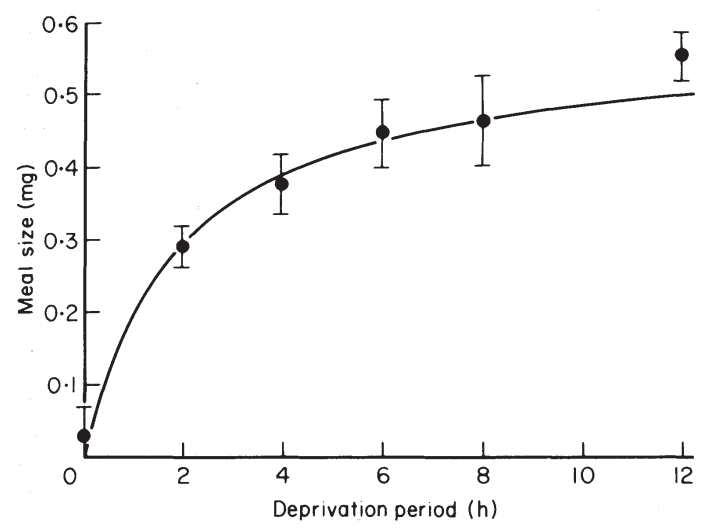

Figure 2. Meal-size curve in Chrysopa larvae. Points indicate weight gained in $30 \mathrm{~min}$ of feeding after the designated period for food deprivation. Values are means and $95 \%$ confidence limits of twenty replications. Curve indicates fit of hyperbolic function: $y=$ $0.581 x /(x+1.99)$.

fed for a consistently greater proportion of the time, although none of the individual differences attained statistical significance. Neither total duration of feeding nor total number of feeding episodes differed significantly between deprivation levels. The mean duration of individual feeding episodes was shorter in lower-deprivation animals, however, and the

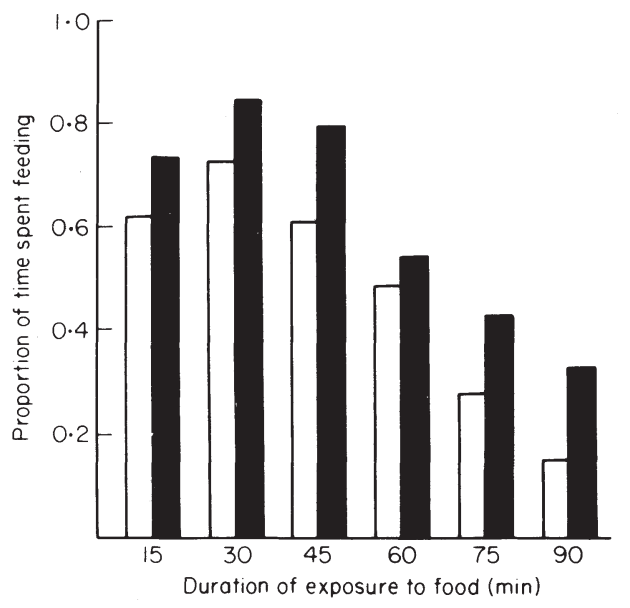

Figure 3. Proportion of time spent by Chrysopa larvae apparently feeding in the presence of excess food, by 15-min intervals. White bars indicate $2 \mathrm{~h}$ deprivation; black bars, $8 \mathrm{~h}$. Values are means of nine replications.

difference was marginally significant $(P<0.05$; one-tailed $t$-test).

\section{Discussion}

No significant weight gain was observed during the last hour of the 90-min feeding periods, even after deprivation for $3 \mathrm{~h}$. $30 \mathrm{~min}$ of ex- 
posure to food must therefore be sufficient for feeding to repletion in Chrysopa and is probably well in excess of the minimum time requirement. Several species of blood-sucking insect can apparently achieve satiety in less than 15 min (Christophers, 1960; Friend, 1965; Galun \& Margalit, 1969).

The continued decrease in the weight of the prey after the larvae have ceased to gain weight could imply that continued ingestion is masked by concomitant excretion during the last hour of the feeding periods. Close examination of five animals during prolonged bouts of feeding, however, revealed no simultaneous excretion. Copious release of dark brown urine was observed only after the animals had completely relinquished the remains of their prey and were resting immobile at some distance from the feeding site. On the other hand, chrysopid larvae commonly consume only a portion of their prey, and fluids will continue to drain from the bodies of punctured aphids for several hours, so that passive leakage of prey body fluids probably explains the sustained weight loss.

The meal-size curve suggests that the highest value is strongly deviant and that the true best estimate of maximum meal size lies well below it. Animals deprived of food for $12 \mathrm{~h}$ apparently undergo a certain degree of wasting, losing weight that cannot be recovered in a single feeding session. These larvae exhibit a lighter post-satiation body weight than their actual gut capacity should warrant, causing the adjusted mean meal size to fall significantly above the fitted curve. If we correct the original data from $12 \mathrm{~h}$ animals for the influence of body weight using only the within-treatment slope estimate, the resulting mean meal size does not differ significantly from that predicted by the hyperbolic function. The relationship between deprivation and meal size in Chrysopa is apparently similar to that described for other insect species (Holling, 1966), in spite of the major difference in gut morphology.

Arzet (1973) found that deprivations of up to $72 \mathrm{~h}$ had no significant effect on feeding in Chrysopa, but his experimental design differed from mine in several crucial respects. He did not standardize the level of satiety in his animals before testing them, and he measured not the amount of food actually consumed, but the number of aphids killed, a variable that bears no necessary relationship to meal size. Additionally, he observed predation over a period of $4 \mathrm{~h}$, sufficiently long for normal maintenance feeding to have obscured any consequences of the deprivation.

Because of the suctorial feeding technique employed by chrysopids, it is seldom possible to tell from direct observation whether ingestion is taking place. If satiety is usually attained during the first $30 \mathrm{~min}$ of exposure to food, however, much of the apparent feeding behavior observed in the later portions of a feeding period must occur in the absence of ingestion. It follows that the behavioral components involved in the initiation of feeding are not directly inhibited by gut distension, although the gradual decline in feeding activity toward the end of the observation period suggests regulation by some long-term, persistent effect of satiety.

There are suggestions in the literature that a physiological distinction between feeding initiation and feeding maintenance may be common to many insect species. Orientation to food and biting behavior are often elicited by different stimuli from those that produce sustained ingestion (Dadd, 1970; Hamamura, 1970). There is also evidence that the earlier components in feeding behavior are less responsive to changes in hunger level (Gardner, 1964; Holling, 1966). In this case, however, persistence in attempting to feed when the larvae are physically incapable of further intake may well be an artifact of requiring them to feed in confinement or on horizontal surfaces.

When chrysopid larvae encounter aphids under more natural conditions, they usually consume them while clinging to the undersides of leaves or hanging head-downward along a stem. In these circumstances, the remains of the aphid drop free of the plant and are lost when the predator first releases its hold. The larva in its natural environment seldom has the opportunity to feed repeatedly on the same prey individual.

In contrast, release of the prey on a horizontal surface does not remove it from continued contact with the predator. Either because the 
sensory units that initiate feeding do not adapt with continued ingestion, or because feeding behavior is generated endogenously and does not require continued exogenous excitatory input to sustain it, efforts to feed are immediately re-initiated. I suggest that larvae do not normally attempt to extend the meal beyond the capacity of the gut, but that the releasing behavior that usually terminates a bout of feeding is incapacitated on horizontal surfaces.

Support for this hypothesis can be found in two sets of observations. First, when chrysopid larvae are deprived for either 2 or $8 \mathrm{~h}$ and then allowed to feed on a single aphid on a vertical rod, the hungrier animals feed for over twice as long as the low-deprivation larvae, and virtually all meals are terminated by releasing the remains of the prey (Bond, 1976). Secondly, the hypothesis implies that animals at lower deprivation levels in the repletion chambers should exhibit shorter individual feeding bouts, as a consequence of attempting more often to break off feeding and terminate the meal. This inference is supported by the results of the experiment on time spent feeding, in which the duration of bouts of apparent feeding behavior was, on the average, shorter for animals at lower deprivation levels.

The results of these three experiments indicate that the general features of regulation of meal size in chrysopids may differ from those described for other insects. Sensory units that excite feeding behavior may not decline in activity early in the meal, or they may produce persistent central excitatory states that maintain feeding efforts even after the receptors themselves have adapted. Under either circumstance, receptor adaptation would be only minimally involved in the regulation of meal size. The gradual decline in apparent feeding behavior may be attributable to some inhibitory neural or humoral consequence of repletion, but the degree of distention of the gut and abdomen cannot be directly responsible. On the other hand, meal duration under more natural conditions is closely tied to the volume of gut contents, implying that the control of meal size in Chrysopa is usually mediated through the stimulation of prey-release behavior, rather than the inhibition of continued feeding. More thorough investigations of the behavioral physiology of these animals will be required, but these preliminary results suggest that generalizations drawn from studies of Phormia or Locusta may be of limited value in describing the control of feeding in predatory Neuroptera.

\section{Acknowledgments}

I wish to thank Dr. G. W. Barlow, Dr. K. S. Hagen, R. L. Tassan, and S. J. Spengler for advice and assistance throughout the course of this study; and Dr. R. H. Dadd and Dr. R. L. Caldwell for critical reading and discussion of the manuscript. This research was supported in part by a predoctoral fellowship from the National Institutes of Mental Health.

\section{References}

Arzet, H.R. (1973) Suchverhalten der Larven von Chrysopa carnea Stephens (Neuroptera:Chrysopidae). Zeitschrift für Angewandte Entomologie, 74, 64-79.

Barton Browne, L. (1975) Regulatory mechanisms in insect feeding. Advances in Insect Physiology, 11, 1-116.

Bond, A. (1976) Hunger and foraging in the green lacewing, Chrysopa carnea Stephens. Unpublished doctoral dissertation, University of California, Berkeley.

Christophers, R. (1960) Aedes aegypti, the Yellow Fever Mosquito: Its Life History, Bionomics, and Structure. Cambridge University Press, London.

Cornish-Bowden, A. \& Eisenthal, R. (1974) Statistical considerations in the estimation of enzyme kinetic parameters by the direct linear plot and other methods. Biochemical Journal, 139, 721-730.

Dadd, R. H. (1970) Arthropod nutrition. Chemical Zoology, 5, 35-95.

Davey, K. G. \& Treherne, J. E. (1963) Studies on crop function in the cockroach (Periplaneta americana L.). I. The mechanism of cropemptying. Journal of Experimental Biology, 40, 763-773. 
Dufort, R. H. \&. Wright, J. H. (1962) Food intake as a function of duration of food deprivation. Journal of Psychology, 53, 465-468.

Eisenthal, R. \& Cornish-Bowden, A. (1974) The direct linear plot: A new graphical procedure for estimating enzyme kinetic parameters. Biochemical Journal, 139, 715-720.

Friend, W. G. (1965) The gorging response in Rhodnius prolixus Ståhl. Canadian Journal of Zoology, 43, 125-132.

Galun, R. \& Margalit, J. (1969) Adenine nucleotides as feeding stimulants of the tsetse fly Glossina austeni. Nature, London, 222, 583-584.

Gardner, B. T. (1964) Hunting and sequential responses in the hunting behaviour of salticid spiders. Journal of Comparative and Physiological Psychology, 58, 168-173.

Green, G. W. (1964) The control of spontaneous locomotor activity in Phormia regina Meigen. II. Experiments to determine the mecha- nism involved. Journal of Insect Physiology, 10, 727-752.

Hamamura, Y. (1970) The substances that control the feeding behaviour and the growth of the silkworm Bombyx mori L. Control of Insect Behavior by Natural Products (ed. by D. L. Wood, R. M. Silverstein, \& M. Jakajima), pp. 55-80, Academic Press, New York.

Holling, C. S. (1966) The functional response of invertebrate predators to prey density. Memoirs of the Entomological Society of Canada, 48,1-86.

Hunt, J. N. \& Spurrell, W. R. (1951) The pattern of emptying of the human stomach. Journal of Physiology, 113, 157-168.

Killington, F. J. (1936) A Monograph of the British Neuroptera, Vol. 1. The Ray Society, London.

Quigley, J. P. \& Louckes, H. S. (1962) Gastric emptying. American Journal of Digestive Diseases, 7, 672-676. 